\title{
Transição para a Parentalidade no Contexto de Cardiopatia Congênita do Bebê
}

\author{
Cristina Saling Kruel ${ }^{2}$ \\ Universidade Federal de Santa Maria \\ Centro Universitário Franciscano \\ Rita de Cássia Sobreira Lopes \\ Universidade Federal do Rio Grande do Sul
}

\begin{abstract}
RESUMO - O estudo objetivou investigar o processo de transição para a parentalidade no contexto de cardiopatia congênita do bebê. Participaram do estudo quatro casais, cujos filhos nasceram com malformação cardíaca. Utilizou-se delineamento de estudo de caso coletivo. Mãe e pai foram entrevistados sobre os primeiros momentos após o nascimento do bebê e a experiência da maternidade e da paternidade, respectivamente. Análise de conteúdo indicou que o diagnóstico de cardiopatia do bebê interfere no processo de parentalização. Destacou-se a intensa preocupação das mães com a sobrevivência dos bebês, evidenciada por meio da dedicação exclusiva a eles. Os pais demonstram-se envolvidos com seus filhos, assumindo também a tarefa de proteger as mães. Conclui-se que os sentimentos relativos à parentalidade focalizaram-se na sobrevivência do bebê.
\end{abstract}

Palavras-chave: maternidade; paternidade; cardiopatia; hospitalização.

\section{Transition to Parenthood in the Context of Congenital Heart Disease}

\begin{abstract}
This study investigated the transition to parenthood in the context of an infant's congenital heart disease. Four couples with a baby suffering from this disease participated in this study. A collective-case study was used. Mothers and fathers were individually interviewed concerning the first moments following the baby's birth and the experience of motherhood and fatherhood. Content analysis indicated that the diagnosis of the baby's heart disease interfered in the parentalization process. The intense maternal concern regarding the baby's survival manifested itself through exclusive dedication to the baby. Fathers were involved with their infants, and also assumed the task of protecting the mothers. It can be concluded that the feelings regarding parenthood focused on the question of the baby's survival.
\end{abstract}

Keywords: motherhood; fatherhood; congenital heart malformation; hospitalization.

O termo parentalidade foi proposto pela primeira vez pelo psicanalista Paul-Claude Racamier que, em 1961, traduziu o termo inglês motherhood por maternalidade, na tentativa de conferir um significado mais dinâmico a esse conceito. Em acordo com tal tradução, o psicanalista acrescenta os neologismos paternalidade e parentalidade.

Houzel (2004) propõe três eixos da parentalidade, em torno dos quais se articulariam as funções adquiridas pelos pais e mães, a saber: exercício da parentalidade, experiência da parentalidade e prática da parentalidade. O exercício da parentalidade aproxima-se do sentido jurídico do conceito e permite a organização de tal construto, na medida em que identifica os laços de parentesco e os direitos e deveres a estes atrelados. A experiência da parentalidade relaciona-se à experiência subjetiva das funções parentais. Dentre os aspectos englobados neste construto destacam-se o desejo de ter um filho, objeto de estudos sistêmicos e psicanalíticos, e o processo de transição em direção à parentalidade, bastante explorado no universo feminino através de termos como preocupação materna primária (Winnicott, 1988) e constelação da maternidade (Stern, 1997), sendo atualmente estudado no universo masculino (Coutinho \& Morsch, 2006;

1 Este estudo é fruto de Dissertação de Mestrado e contou com apoio financeiro do CNPq.

2 Endereço para correspondência: Rua Conde de Porto Alegre, 961/302. Santa Maria, RS. CEP: 97015-110. E-mail: criss.psico@terra.com.br
Oiberman, 1994). Já a prática da parentalidade refere-se aos cuidados físicos e psicológicos e às tarefas cotidianas que os genitores realizam junto à criança.

Considerando a experiência da maternidade, percebe-se que, desde as primeiras semanas de gravidez, o equilíbrio físico e psicológico habitual da mulher é alterado. Especialmente ao final da gravidez, há um redirecionamento do investimento materno, que se desliga mais do mundo externo e se volta para o bebê, estado este que é denominado por Winnicott (1988) de preocupação materna primária. Esse estado especial da mãe faz com que ela seja capaz de sintonizar-se com o bebê através de uma intensa capacidade de identificação.

Stern (1997) acredita que após o nascimento do bebê a mãe entra em uma nova e única organização psíquica, por ele denominada de constelação da maternidade. Essa nova organização, que surge especialmente após o nascimento do primeiro filho e que é temporária, determina mudanças de ação, fantasias, medos, sensibilidade e desejos da mulher. Sendo assim, durante o período que perdura a constelação da maternidade, que pode ser de meses ou anos, ela se configura como o eixo organizador dominante na vida psíquica da mãe. $\mathrm{O}$ autor destaca quatro temas e tarefas que constituem a constelação da maternidade, a saber, o tema vida-crescimento, que se relaciona à capacidade materna de manter vivo o bebê; o tema relacionar-se primário, que se refere à capacidade de envolver-se emocionalmente com o bebê, o tema da matriz 
de apoio, relativo à capacidade materna em criar e permitir sistemas de apoio necessários ao bebê; e o tema da reorganização da identidade, que se refere à capacidade materna de transformar sua auto-identidade. Considerando todos esses temas, torna-se importante destacar que, para Stern, a constelação da maternidade não é universal, nem mesmo inata, sendo influenciada por fatores sociais, histórico-culturais e psicobiológicos, especialmente hormonais.

Segundo Oiberman (1994), a maternidade e a paternidade são funções complementares que se desenvolvem em uma estrutura cultural e familiar. O pai permaneceu durante décadas ocupando lugar de provedor e garantidor de limites e leis familiares, afastando-se da realidade doméstica e de seus filhos, concepção que vem sofrendo transformações nos últimos 30 anos. A mudança de papéis paternos na dinâmica familiar foi desencadeada pela inserção da mulher no mercado de trabalho e, a partir da década de 1970, o pai passou a ocupar um espaço mais significativo na criação de seus filhos (Lamb, Pleck, Charnov, \& Levine, 1985).

A mudança de postura paterna despertou o interesse de antropólogos, psicanalistas e demais estudiosos do comportamento humano, o que ocasionou o surgimento de diversos conceitos que buscam compreender tal movimento. Dentre os conceitos emergentes, o de "novo pai" busca caracterizar aquele homem que se compromete com os cuidados de seus filhos (Oiberman, 1994), investindo em vínculos afetivos intensos e representando a possibilidade de ruptura com o modelo tradicional de pai (Freitas, Coelho \& Silva, 2007).

Outro conceito que vem sendo estudado é de envolvimento paterno, que se tornou foco de estudos recentes, sendo caracterizado de diversas maneiras (Silva \& Piccinini, 2007). Dentre as acepções utilizadas, encontra-se a proposta por Lamb et al. (1985), que sugerem que os elementos que integram esta nova conduta são a interação, a acessibilidade e a responsabilidade dos pais. A avaliação da interação considera o tempo que o pai permanece junto ao seu filho, desenvolvendo atividades conjuntas. A acessibilidade é avaliada a partir da presença ou disponibilidade do pai na efetivação das interações. Já a responsabilidade se refere ao provimento de cuidado e recursos para as atividades de seu filho, como, por exemplo, escolaridade, saúde, participação em grupos sociais.

Assim, torna-se possível pensar em um potencial paterno inato para a dedicação ao filho, que é chamado, por alguns autores, engrossment ${ }^{3}$. Para Oiberman (1994), tal conceito refere-se a um potencial inato do pai que aflora no momento do nascimento do bebê e implica estar totalmente absorvido pela presença do bebê, manifestar preocupação e interesse, expressar emoção diante do nascimento e emocionar-se intensamente ao sentir-se pai.

A transição para a parentalidade é um processo que se inicia antes mesmo do nascimento do primeiro filho do casal, mas permanece em constante construção, podendo provocar diferentes repercussões na vida do homem e da mulher (Brazelton \& Cramer, 1992; Soifer, 1980; Szejer \& Stewart, 1997). Neste contexto, o surgimento de uma grande carga de expectativas com relação ao bebê é inevitável e esta criança

3 Engrossment é uma palavra que não possui tradução para a língua portuguesa. será imaginada a partir das impressões e desejos advindos da experiência da gestação, bem como de vivências anteriores dos genitores (Caron, 2000; Soifer, 1980; Soulé, 1987). Após a espera durante os nove meses de gestação, o nascimento de uma criança com malformação cardíaca pode precipitar sentimentos intensos, incrementando as dificuldades desse período (Klaus, Kennell \& Klaus, 2000).

A partir deste momento, pai e mãe enfrentam sentimentos de luto intenso, mesmo não tendo havido a morte concreta do bebê, pois o filho que nasceu se distancia ainda mais daquele bebê perfeito que foi idealizado (Klaus et al., 2000). $\mathrm{O}$ confronto do bebê imaginário com o bebê real ocorre em situações nas quais o bebê nasce sem nenhum tipo de malformação, pois a criança que os genitores enxergam nos primeiros momentos após o parto não corresponde às expectativas desenvolvidas durante a gravidez (Lebovici, 1992). Nos casos de anormalidade congênita, este confronto assume uma dimensão maior (Klaus \& Kennell, 1992; Klaus et al., 2000).

Considerando-se a importância desta temática, as pesquisas sobre o diagnóstico de cardiopatia congênita e seu impacto na família vêm se tornando progressivamente mais frequentes no panorama internacional, nos últimos anos, havendo um aumento de publicações entre os anos de 2002 e 2009, dado que deflagra o interesse atual dos pesquisadores sobre o tema. Porém, em pesquisa nos bancos de dados PsycoInfo (1980-2009), IndexPsi (1980-2009) e Lilacs (1980-2009), foi encontrado um número limitado de pesquisas sobre aspectos psicológicos no contexto de cardiopatia congênita. Dentre os estudos nacionais, foi encontrada uma pesquisa que atentou para a vivência de mães de crianças portadoras de cardiopatias (Ribeiro \& Madeira, 2006).

Valorizando a instrumentalização de profissionais que atendem pais e mães de crianças com cardiopatia congênita, as enfermeiras Ribeiro e Madeira (2006) procuraram estudar tal evento através de uma abordagem fenomenológica. As pesquisadoras entrevistaram mães de crianças com cardiopatia internadas em um centro de cardiologia infantil, e foi possível concluir que a vivência de cada mãe é bastante singular, portanto, a conduta da equipe de enfermagem deve basear-se nas falas das mães, que indicam seus temores, dúvidas e limitações e não em teorias pré-estabelecidas.

Os demais trabalhos nacionais encontrados foram artigos de revisão e tiveram como foco o papel da ultrassonografia e a relação materno-fetal nas situações de normalidade e anormalidade fetal (Gomes \& Piccinini, 2005), não atentando, neste caso, para as malformações cardíacas especificamente. Também revisaram as repercussões do diagnóstico na família (Quayle, Neder, Mihaydaira, \& Zugaib, 1996), parentalidade e medicina fetal (Quayle, 1997) e representações associadas ao diagnóstico pré-natal (Quayle, Isfer \& Zugaib, 1991). Já os estudos internacionais que investigaram fatores psicológicos foram desenvolvidos, em sua maioria, por pediatras, obstetras, enfermeiros e psiquiatras, o que demonstra que esse é um tema pouco explorado por psicólogos. As pesquisas priorizam análises quantitativas, através de grupos comparativos e investigam temas como o impacto da ecocardiografia no contexto de normalidade e anormalidade fetal (Kovalchin \& Silverman, 2004), o aconselhamento a pais e mães que descobrem a malformação cardíaca do filho durante a gestação 
Tabela 1. Caracterização dos participantes e momento do diagnóstico.

\begin{tabular}{lllll}
\hline Caso & $\mathbf{1}$ & $\mathbf{2}$ & $\mathbf{3}$ & $\mathbf{4}$ \\
Mãe & Sandra & Rafaela & Fabiola & Lenir \\
\hline Idade & 24 & 20 & 29 & 25 \\
Estado Civil & Solteira & Solteira & Casada & Solteira \\
Escolaridade & Ensino médio incompleto & Ensino médio & Graduada & Ensino médio \\
Profissão & Do lar & Auxiliar financeira & Administradora & Do lar \\
Pai & Roberto & Marcos & Adriano & Aldair \\
\hline $\begin{array}{l}\text { Idade } \\
\text { Estado Civil }\end{array}$ & 20 & 20 & 36 & 21 \\
Escolaridade & Solteiro & Colteiro & Pós-graduado & Solteiro \\
Profissão & Ensino fundamental & Ensino médio & Ensino fundamental \\
& Pedreiro & Operador de caixa & Administrador & Servente de pedreiro \\
Bebê & & & Patrícia & 20 dias \\
\hline Idade do bebê & Karina & Gabriel & Gestação & Murilo \\
Momento do Diagnóstico & 10 dias & Horas após o parto & & $2 \mathrm{~m}$ 5dias \\
\hline
\end{tabular}

(Menahem \& Grimwade, 2005), o processo de transição para a parentalidade (Svavarsdottir \& McCubbin, 1996), níveis de ansiedade e depressão das mães (Rona, Smeeton, Beech, Barnett \& Sharland, 1998) e interação mãe-bebê (Gardner, Freeman, Black \& Angelini, 1996).

Os estudos internacionais também têm como foco a adaptação dos genitores ao nascimento da criança com deficiência, incluindo a malformação cardíaca (Pelchalt et al., 1999), a qualidade de vida (Goldbeck \& Melches, 2005; 2006; Wray \& Maynard, 2004), a percepção e entendimento dos genitores sobre a malformação (Cheuk, Wong, Choi, Chau, \& Cheung, 2006; Lok \& Menahem, 2004), práticas maternas (Carey, Nicholson, \& Fox, 2002), estresse (Uzark \& Jones, 2003), o papel do enfermeiro, enquanto provedor de apoio a famílias com crianças com cardiopatia (Griffin, 2002).

$\mathrm{O}$ crescente número de pesquisas sobre relações familiares no contexto de cardiopatia congênita demonstra que esta é uma temática que tem despertado o interesse de profissionais de diversas áreas. Porém, são escassas as pesquisas sobre o impacto do nascimento de uma criança com diagnóstico de cardiopatia congênita na transição para a parentalidade, o que justifica a necessidade de que a experiência dos pais e mães dessas crianças seja estudada. Considerando o exposto anteriormente, o presente estudo tem como objetivo investigar o processo de transição para a parentalidade no contexto de cardiopatia congênita do bebê.

\section{Método}

\section{Participantes}

Participaram deste estudo quatro pais e quatro mães, com idade entre 21 a 35 anos (Tabela 1), que receberam o diagnóstico de cardiopatia congênita de seu primeiro filho. As crianças tinham idade entre 10 e 90 dias de vida. Todos os casais coabitavam e tinham escolaridade e nível sócio-econômico variado. Os bebês não tinham diagnóstico de quaisquer outras anormalidades fetais, além da cardiopatia fetal e estavam hospitalizados em Unidade de Tratamento Intensivo (UTI), em período pós-cirúrgico.

\section{Delineamento e procedimentos}

Foi utilizado delineamento de estudo de caso coletivo (Stake, 1994). Os casais foram convidados a participar do estudo por meio de um hospital que atende crianças portadoras de cardiopatia congênita. Aqueles que aceitaram, preencheram uma ficha de contato inicial (GIDEP4, 1998a). Uma vez confirmado o interesse pela participação e os critérios de inclusão no estudo, foi lido e assinado o Termo de Consentimento Livre e Esclarecido (GIDEP, 1998b).

Posteriormente, foi preenchida a ficha de dados demográficos do Casal, (GIDEP, 1998c) e foram realizadas as entrevistas em uma pequena sala que ficava ao lado da sala de espera da UTI no próprio hospital. Foram entrevistados todos os casais que se enquadravam nos critérios de inclusão do estudo e estavam com seus filhos internados no hospital durante o período de coleta de dados. Foi realizada uma entrevista individualmente com a mãe e outra com o pai sobre os primeiros momentos após o nascimento do bebê com malformação e a experiência da maternidade e paternidade, respectivamente.

Os participantes deste estudo foram informados, desde o primeiro contato, sobre os objetivos do mesmo e a forma de

4 Grupo de Interação, Desenvolvimento e Psicopatologia - GIDEP/ UFRGS/CNPq 
coleta e análise dos dados e puderam decidir livremente sobre a disponibilidade de participarem do estudo. Em nenhum momento do estudo os participantes foram identificados, pois foram utilizados nomes fictícios. O estudo foi submetido e aprovado pelo Comitê de Ética do Hospital da Criança Santo Antônio (HCSA).

\section{Resultados e Discussão}

Os dados do presente estudo foram examinados através de análise de conteúdo qualitativa, proposta por Laville e Dionne (1999). Através dos casos estudados, buscou-se investigar os aspectos psicológicos envolvidos no processo de transição para a parentalidade no contexto de cardiopatia congênita do bebê. Análise de conteúdo foi realizada a partir do recorte das falas dos pais, que foram organizadas em categorias temáticas, estabelecidas com base na literatura revisada, bem como durante a análise dos dados.

Para fins de discussão, foram elencados dois eixos, a saber, Eixo I, que discutiu aspectos referentes ao Diagnóstico e às repercussões na parentalidade, e o Eixo II, que abordou aspectos relativos à Parentalidade - tornar-se pai e tornar-se mãe no contexto de cardiopatia congênita do bebê, subdividido em experiência da maternidade e experiência da paternidade.

\section{Eixo I - O momento do diagnóstico e seu impacto na parentalidade}

Os oito participantes do estudo viram-se tomados por uma avalanche de sentimentos, desde a notícia da gravidez até o momento em que foram entrevistados. Percebeu-se que o diagnóstico de um defeito no coração, órgão vital, mobiliza nos pais e mães sentimentos intensos de impotência e medo diante da possibilidade de morte do bebê: "E problema no coração é complicado! E pra ti conseguir um coração doador é muito complicado. Se é uma outra parte, um pai pode doar, uma mãe pode doar, né?. Não o coração que é uma parte né que super.... faz funcionar tudo, né? Se eu não tenho coração, não tem vida, né. O coração é o pior problema que pode dar! A criança pode nascer sem uma mãozinha, com defeitinho, sabe? Mas o coração é... Pra mim é a pior coisa que pode acontecer! (...) O coração é tudo, né? O coração, se não funcionar deu, né. Pode tudo funcionar, mas o coraçãozinho parou, deu! Parou, parou, né? Não tem mais" (Marcos)

Dentre as sensações advindas da notícia do diagnóstico de malformação cardíaca do bebê que puderam ser nomeadas pelos pais e mães, o desamparo esteve presente em todos os casos. Além deste sentimento e outras reações comuns a todos os participantes, cada um percorreu caminhos distintos, na busca por adaptar-se à condição de pai e mãe de uma criança com malformação cardíaca. Neste contexto, o momento no qual o diagnóstico foi comunicado aos pais e mães parece ter interferido significativamente no processo de transição para a parentalidade. Sobre este aspecto, os participantes do estudo tiveram experiências singulares, pois, conforme mostra a Tabela 1, um casal recebeu a notícia durante a gestação e os outros três casais foram comunicados sobre o diagnóstico após o nascimento do bebê.

Considerando o diagnóstico fornecido durante a gestação, foi possível perceber que a notícia precoce não consentiu à Fabiola experimentar sentimentos maternos mais intensos. O choque do diagnóstico teve como conseqüência a interrupção do processo psíquico normal de gestação. A partir deste momento, ela sentiu-se incapaz de prever seu futuro com o bebê, desinvestindo emocionalmente em seu vínculo com ela. Esta reação configura-se, conforme Maldonado (1997), como uma forma de defesa da mulher, que resguarda seus sentimentos maternos até que haja a confirmação da possibilidade de sobrevida do bebê: "Quando foi diagnosticado, eu pensei, ai, meu Deus, por que eu, né?... Por que eu fui escolhida, né? ... Eu soube do problema dela quando estava com cinco meses de gestação. Pra gente, aquilo lá foi o fim. Aí eu falava pra minha mãe, que motivação eu vou ter pra fazer um quartinho? Pra arrumar as coisas? .... Eu fiquei uma semana revoltada, sem saber o que fazer. Eu não vou fazer, eu não vou comprar nada, não vou fazer nada!"

É possível pensar que os primeiros dias após a confirmação do diagnóstico foram vivenciados pela mãe com intensa tristeza, conforme ela explicitou na entrevista. Porém, após este período, a Fabiola passou a negar o problema através da utilização de mecanismos defensivos egóicos: “... a gente tratou a gestação, assim, como se fosse uma gestação normal, assim, tanto é que ela trabalhou até um mês antes do parto... E até uns quarenta dias antes, assim, ela tava sempre fazendo ginástica, fazia academia, mas academia mais leve, assim, pra gestante e tal. (...) Foi tranqüilo, foi tudo normal, a gente tentou tratar tudo dentro da máxima normalidade..." A negação implantou-se a serviço de permitir a saúde psíquica de Fabiola, em contrapartida, não permitiu que a mãe vivenciasse o processo de luto, o que teve repercussões futuras que serão discutidas no eixo sobre o período de hospitalização.

Pode-se pensar que o diagnóstico prematuro permite ao pai e a mãe mais tempo para adaptar-se à situação (Kroeff, Maia \& Lima, 2000), bem como lançar mão de defesas, o que facilitaria o manejo da crise consequente do diagnóstico (Quayle, 1997). Somado a isto, alguns autores sugerem que a vivência do processo de luto pela perda do bebê imaginário ainda durante a gestação poderia garantir uma maior disponibilidade de contato entre o pai, mãe e o bebê nos primeiros momentos de vida deste. $\mathrm{O}$ diagnóstico precoce também permite o estabelecimento de metas e condutas médicas, bem como o atendimento adequado às necessidades da criança logo após o parto, o que reduz consideravelmente os riscos de morte neonatal (Quayle et al., 1991).

Porém, cabe ressaltar que a gravidez configura-se como um período no qual o pai e a mãe podem preparar-se para vincular-se ao bebê. Além disso, mesmo que o processo de transição para a parentalidade se inicie durante a gravidez, alguns pais sentem-se envolvidos neste processo somente após o nascimento do bebê (Freitas et al., 2007).

Então, pode-se inferir que Fabiola e Adriano sofreram uma interferência prematura em seus processos de parentalização, em um período no qual suas identidades materna e paterna estavam se constituindo. Neste contexto, o pai e a mãe viram-se precocemente confrontados com a possibilida- 
de real de morte de seu bebê. Fabiola inicialmente evitou o estabelecimento de laços afetivos com o bebê, como forma de proteção dos sentimentos intensos que poderiam se manifestar, em caso de morte fetal. Considerando este caso, pai e mãe puderam resgatar seus vínculos com sua filha após o nascimento desta, o que se tornou possível através do apoio mútuo e familiar.

A interferência precoce do diagnóstico de malformação cardíaca do bebê também foi vivenciada por Rafaela, que recebeu a notícia poucas horas após o nascimento do bebê. Gabriel foi afastado da mãe para que fosse examinado mais detalhadamente, porém este afastamento parece ter contribuído para o processo de luto antecipatório (Klaus \& Kennell, 1992), expresso pela experiência de vazio experimentada pela mãe: "Tiraram assim um braço meu". Nestes primeiros momentos após o parto, a mãe fica descentrada, como se o bebê tivesse mantido seu centro de gravidade durante os últimos meses. Este desequilíbrio transitório e essencial insere a mulher em um estado de fragilidade psíquica, no qual ela experimenta intensas emoções (Szejer \& Stewart, 1997).

$\mathrm{O}$ fato de o diagnóstico ter sido fornecido logo após o nascimento do bebê fez com que Rafaela sentisse que seu filho estava protegido em seu útero: "Não porque pra mim assim, ele precisa de mim né, não dos outros (...) É coladinho na barriga. (...) Parece que tá... que é ligado em mim sabe? Um pedaço de mim. Realmente é um pedaço de mim".

Então, parece que, tanto para Fabiola quanto para Rafaela, os diagnósticos foram precoces. Ambas souberam da malformação cardíaca enquanto não haviam experimentado a maternidade na presença do bebê. Neste sentido, pode-se pensar que, quanto mais precoce, o diagnóstico mais difícil é para a mãe superar o impacto deste.

Já as demais mães participantes do estudo receberam o diagnóstico de cardiopatia do bebê dias após o parto. Lenir e Sandra puderam experimentar a maternidade de maneira mais intensa logo após o nascimento do bebê, pois ambas receberam alta hospitalar poucos dias após o parto e cuidaram de seus filhos até o dia em que foram comunicadas sobre o diagnóstico. Dessa forma, elas demonstraram pesar pelo pouco tempo de permanência com os bebês. Sandra disse que "ele ficou só oito dias em casa" e Lenir contou que achou "que o nenê não ia precisar fazer agora a cirurgia, um pouco mais tarde".

Torna-se importante destacar, em relação a este tema, que o pai não sofreu o mesmo impacto do momento do diagnóstico quando comparado à mãe. Tal idéia reporta ao estudo desenvolvido por Lawoko e Soares (2002), que buscou comparar as experiências paternas e maternas. Os autores destacaram que as mães possuíam níveis mais elevados de estresse e desesperança no momento do diagnóstico e malformação do bebê, comparadas aos pais. $\mathrm{O}$ envolvimento físico da mãe com o bebê, consequente do período gestacional, pode levar a um sentimento mais intenso de responsabilidade pela manutenção da vida da criança, o que repercute em maior impacto nas mães no que se refere ao momento em que a notícia é comunicada. Pode-se pensar que os pais participantes do estudam estiveram bastante envolvidos e preocupados com seus bebês, porém a qualidade do envolvimento é diferente, na medida em que não havia o envolvimento físico proporcionado à mãe pelo período gestacional.

\section{Eixo II - Parentalidade: tornar-se pai e tornar-se mãe no contexto de cardiopatia congênita do bebê}

O diagnóstico de cardiopatia do recém nascido sugere a necessidade de correção cirúrgica imediata seja paliativa ou definitiva (Jatene, Oliveira \& Moysés, 2007). Tal intervenção implica na permanência da criança e dos genitores no ambiente hospitalar. Neste contexto, surgem questionamentos sobre a experiência da maternidade e da paternidade. Em virtude das singularidades das experiências paternas e maternas, optou-se por dividir este tema, observando, inicialmente a experiência das mães e, posteriormente, dos pais.

\section{A experiência da maternidade}

Conforme anteriormente exposto, Stern (1997) acredita que, quando a mulher se torna mãe na cultura ocidental, emergem quatro temas relacionados ao que ele denomina constelação da maternidade, a saber, vida-crescimento, relacionar-se primário, matriz de apoio e reorganização da identidade. Considerando o tema vida-crescimento, pode-se perceber que todas as mães participantes do estudo demonstraram medo constante de que seus bebês morressem. A possibilidade de morte do filho era confirmada pelos óbitos de outros bebês, que se encontravam hospitalizados e que, muitas vezes, eram portadores de malformações semelhantes à do seu.

Além disso, as mães demonstraram ter consciência de que a atuação prática delas em relação aos cuidados ao bebê era limitada, considerando o quadro de saúde das crianças. Então, todas se mantinham tão próximas quanto possível de seus bebês, uma vez que consideravam que suas presenças eram importantes para a boa evolução do quadro de saúde dos filhos. É interessante atentar para este fato, pois ele denota que as mães sentiam-se importantes para a manutenção da vida dos bebês, mesmo eles estando sob cuidados médicos.

Outro fato importante é que Stern (1997) se refere à tarefa vida-crescimento nos primeiros dias de vida do bebê, período no qual mãe e o bebê ainda estão se adaptando um ao outro. Então, percebe-se outra particularidade na experiência destas mulheres, pois elas permaneceram mais tempo lutando para manter vivos seus filhos. Parece haver um prolongamento da tarefa vida-crescimento.

A respeito do tema relacionar-se primário, percebe-se que as mães tiveram experiências distintas. A começar por Fabiola, que recebeu o diagnóstico durante a gestação e sofreu reflexos deste diagnóstico precoce. Percebe-se que ela negou a presença de malformação em seu bebê durante o período gestacional, não se permitindo sofrer. Apesar de este mecanismo ter tornado possível à mãe uma gravidez mais tranqüila, somente a vivência do luto pela perda do bebê perfeito possibilitaria a adaptação à nova realidade, que, conforme Quayle (1997) permite à mãe dedicar-se e cuidar do bebê. 
Fabiola resistiu ao primeiro encontro com a filha, pois temia sua reação diante da aparência de Patrícia e não se sentia preparada para vê-la na UTI: "Meu Deus! Eu não quero ver, eu não quero ver! Eu não vou ter coragem, eu não vou ter coragem de encarar, entendeu?" Considerando o medo e insegurança, sentidos por Fabiola neste momento, pode-se pensar que, mesmo ela tendo conseguido superar os momentos de revolta mais intensos logo após o diagnóstico, a sensação de desamparo retornou em outros momentos após o nascimento do bebê.

Alguns pais e mães podem preferir evitar o encontro com seu bebê, pela necessidade de amenizar o impacto desta experiência. Nestes casos, o encontro deve ser incentivado, considerando o estado emocional dos genitores, pois a visão do filho pode ter efeito propulsor de sentimentos de carinho e proteção em relação ao mesmo. Quanto mais tempo a mãe leva para ver seu filho pela primeira vez, mais ela poderá alimentar fantasias equivocadas sobre o estado de saúde da criança. Em contrapartida, quanto mais cedo o encontro com o bebê, mais rápida será a conciliação entre sua imagem mental e as condições reais dele (Klaus \& Kennell, 1992).

Neste momento, encorajar a mãe a falar de seus sentimentos pode ser de grande valor (Klaus \& Kennell, 1992). O desgaste do primeiro encontro pode reverter-se em benefícios à mãe e, principalmente, à relação com o bebê. De fato, Fabiola sentiu-se fortalecida após o encontro com sua filha, pois o primeiro grande desafio havia sido superado.

Considerando as experiências de Sandra, Lenir e Rafaela, nota-se que estas demonstraram estar muito envolvidas com seus bebês. Dentre os fatores que denotam a presença de vínculos afetivos entre mães e bebês hospitalizados estão o contato olho-a-olho, o contato íntimo com o bebê durante a amamentação e as carícias, beijos e batidinhas (Klaus \& Kennell, 1992), comportamentos relatados por estas: “Quando eu tô aqui eu ia muito na UTI, eu fico brincando com os dedinhos dele, de agarrar, passando a mão na cabecinha dele, sempre cuidando pra não se mexer, por causa dos fios que ainda estão tudo presos nele" (Lenir)

Em relação ao tema matriz de apoio, percebe-se que as mães consideram importante a presença de familiares e amigos, no entanto, o apoio aceito por elas é instrumental, isto é, se refere ao auxílio financeiro, divisão de responsabilidades e atividades burocráticas do hospital. No que diz respeito aos cuidados com os bebês, todas as mães participantes do estudo preferiam elas próprias realizarem de maneira bastante solitária, apesar da presença de familiares e amigos: "E eu não gosto muito que os outros fiquem me ajudando. É sempre só eu sabe? (...) Até a minha mãe gosta de me ajudar bastante, mas eu não faço questão (...)Então, de uns 10 dias pra cá eu só fico aqui, durmo aqui e tudo, tomo banho aqui" (Rafaela).

$\mathrm{O}$ último tema proposto por Stern (1997) refere-se à necessidade da mãe de transformar sua identidade, reorganizando-a para atentar a novas preocupações. Considerando as experiências das mães do presente estudo, pode-se pensar que o realinhamento de interesses e preocupações se manifestou de maneira acentuada, uma vez que estas foram levadas a dedicar-se exclusivamente ao bebê, permanecendo grande parte de seus dias no hospital. $\mathrm{O}$ bebê não somente passou a ser a preocupação central da mãe, como se apresentou como a única preocupação, para a qual a mãe dedica toda a sua energia e investimentos emocionais

A reorganização da identidade destas mulheres aconteceu de maneira brusca e intensa, pois elas estavam preparando-se para serem mães de crianças saudáveis. Ser mãe de um bebê com cardiopatia congênita implica conviver com a possibilidade de morte iminente da criança, exercer a maternidade no ambiente hospitalar e manter o otimismo quanto à possibilidade de melhora do quadro de saúde do bebê. Este otimismo permite às mães investirem emocionalmente em seu vínculo com o bebê.

\section{A experiência da paternidade}

O conceito de envolvimento paterno vem sendo caracterizado de diferentes maneiras por pesquisadores da área da psicologia do desenvolvimento (Silva \& Piccinini, 2007). Dentre as definições de envolvimento paterno mais bem aceitas e utilizadas na literatura internacional, encontra-se a proposta por Lamb et al. (1985). Os autores sugeriram três elementos a serem avaliados considerando o envolvimento paterno, a saber, interação, acessibilidade e responsabilidade.

Considerando a interação e a acessibilidade, é possível notar que todos os pais procuraram manterem-se próximos ao bebê, demonstrando estarem absorvidos pela presença dele, manifestando preocupação e interesse quanto ao quadro de saúde dos mesmos e, principalmente, buscando alternativas para auxiliar no processo de cura de seus filhos. Cada um dos pais pereceu estar vivenciando o engrossment à sua maneira (Oiberman, 1994). A exemplo disso, Adriano soube que alguns pais costumavam contar histórias aos filhos hospitalizados e, em seguida, tratou de providenciar um livro de histórias para entreter Patrícia: “...sempre quando eu tenho um tempinho, que eu tô ali do lado dela, eu tô lendo pra ela, eu tô tentando, enfim, mostrar que eu tô presente, porque eu acho que uma coisa é tu tá do lado e outra coisa é tu tá realmente presente ali naquele momento".

Roberto sentia que a sua presença era fundamental para o bem-estar da filha, então mantinha-se próximo, reparando, inclusive, nos sinais de melhora e piora no quadro de saúde da menina. Aldair emocionava-se ao contar que já havia sido feliz, mas nunca havia experimentado sentimentos tão intensos quanto aqueles vivenciados com o filho. Já Marcos envolveu-se com tarefas tipicamente maternas. Em alguns momentos, ele chegou a assumir os cuidados ao filho durante um dia inteiro para que a esposa pudesse descansar, dispensando, inclusive, a ajuda da sogra: "E eu ficava o dia todo, era só eu de pai ali na volta. (...) só eu de pai e trocava a fralda, pegava água lá no banheiro, pra trocar, né? Caia o bico eu ia lá lavar. Pedia o álcool limpava o biquinho. Trocava, dava dorzinha e ficava com ele no colo".

Assim, cada afastamento gerava ansiedade e preocupação, o que, para Adriano e Aldair, era amenizado pela certeza de que os filhos estavam sendo atendidos por bons profissionais. Já para Marcos e Roberto, o afastamento era associado, prioritariamente, ao receio de morte ou agravamento do quadro de saúde das crianças. Desta maneira, estes pais sentiam que de alguma forma as suas presenças minimizavam estes riscos e, além disso, eles tinham medo de que suas esposas 
ficassem desamparadas ou não soubessem como proceder, caso alguma intercorrência acontecesse.

O envolvimento dos pais era bastante intenso e Roberto era capaz de perceber as mudanças que ocorreram em sua vida após o nascimento de sua filha e a sua proximidade afetiva com o bebê lhe permitia manter uma relação empática intensa: "E quando falam assim que ela tá mal, que tá ocorrendo isto, isto e isto, bom aí me dá um aperto assim ó (...) E depois que eu peguei ela no colo e mudou tudo a minha vida. Totalmente. Que agora tudo é a minha filha. (...) Que mudou, sei lá, parece assim, um pedaço da gente". Da mesma forma, Aldair sabia dos riscos atrelados à malformação cardíaca congênita e sentia medo de que seu filho viesse a falecer: "Se acontecer alguma coisa com ele, assim, eu não... Não sei o que pode, o que pode ser de mim...".

Em se tratando da responsabilidade, que se refere ao provimento de cuidado ao filho, bem como preocupações, expectativas e ansiedade em relação a ele (Lamb et al., 1985), os pais participantes do estudo responsabilizaram-se por prover um cuidado especial aos seus bebês, principalmente, por garantir aos filhos a presença e cuidados maternos. Assim, dentre as características parentais assumidas pelos homens participantes deste estudo, a que mais chama atenção é a postura, adotada por todos eles, de proteger suas companheiras e, por consequência, a relação mãe-bebê.

Desta maneira, Marcos buscava manter uma postura otimista: "Ela chorava e eu. Sabe? Também com vontade só que eu não podia, né? Tinha que dizer: Não, ele vai ficar bom! Vão conseguir um leito já, não fica assim. Eu não podia demonstrar pra ela que eu também tava triste, né, porque senão...". Assim como Adriano, que percebia a importância de que sua esposa se sentisse amparada: "Mas a todo momento eu me mantive forte, assim, até pra dar um maior apoio pra Fabiola, assim... porque eu sabia que naquele momento o mais importante era que ela ficasse segura de que fosse correr tudo bem”. Já Roberto poupava sua companheira de notícias desagradáveis: "Muitas coisas eu não gosto de conversar com ela, eu pego e fico pra mim...”. (Roberto)

Os pais tiveram papel fundamental, pois assumiram a função de apoiar e cuidar de suas companheiras, possibilitando-lhes que se dedicassem integralmente às necessidades dos bebês. Winnicott (1988) assinala que é papel do pai apoiar a mãe neste estado de preocupação materna primária, período no qual ela se encontra vulnerável e com maior sensibilidade. Tal postura denota a sensibilidade paterna, que permitiu aos pais sintonizar-se com seus filhos, percebendo suas reais necessidades neste período inicial, que se refere à dependência absoluta.

Cabe ainda ressaltar que os pais sentiam-se ansiosos e preocupados cada vez que necessitavam afastar-se do hospital. Eles sentiam que de alguma forma as suas presenças minimizavam os riscos de morte ou agravamento do quadro de saúde de seus filhos e, além disso, eles tinham medo de que suas esposas ficassem desamparadas ou não soubessem como proceder, caso alguma intercorrência acontecesse: “... eu não tenho condições de pegar e sair de perto dela ou ir pra minha cidade. Eu não posso ficar longe dela" (Roberto). Marcos dormia algumas noites no hospital: "Fiquei sentado ali a noite toda e coloquei meu celular pra despertar de duas em duas horas, sabe? (...)Eu tenho medo que aconteça alguma coisa e eu não to aí, né?"

Para finalizar, torna-se importante salientar que o envolvimento intenso dos pais com seus bebês, a preocupação constante com o bem-estar da companheira e a tentativa de manutenção do otimismo de toda a família frente ao quadro de saúde da criança, levam a uma sobrecarga destes pais que tentavam manejar suas próprias aflições e amenizar o sofrimento do bebê e da mãe. Os pais portaram-se como fortalezas e forneciam cuidados em um momento em que deveriam ser amparados. Destaca-se, então, a importância do apoio psicológico aos homens que passam por esta intensa experiência.

\section{Considerações Finais}

Os resultados do presente estudo indicaram que a notícia da malformação cardíaca do bebê interfere no processo de parentalização de pais e mães de maneira muito intensa. O momento no qual o diagnóstico foi descoberto, bem como a maneira como foi informado, causaram impacto, afetando a vivência da hospitalização e, principalmente, a parentalidade.

Com relação à maternidade, pode-se concluir que as mães ficaram atentas aos bebês, mantendo-se tão próximas a eles quanto possível. Dentre as tarefas da Constelação da Maternidade, destacou-se o tema vida-crescimento, proposto por Stern (1997), cujo foco é a capacidade materna de manter vivo o seu bebê. Conforme o autor, essa tarefa estaria presente para a mãe nos primeiros dias de vida do bebê, porém observa-se que estas mães ainda se encontravam imersas nesta preocupação, pois havia risco de morte do filho. Ainda pode-se pensar que a tarefa vida-crescimento se manteria, integrando as preocupações maternas, durante todo o período de hospitalização do bebê.

A proximidade entre a mãe e o bebê vai ao encontro do desejo destas mulheres de experenciar a maternidade. Foi possível notar que as mulheres ansiavam por assumir suas tarefas, desejo que era incrementado pelo fato de elas estarem vivenciando esta experiência pela primeira vez.

Já para os pais, o apoio à companheira parece ter se mantido enquanto preocupação central. Porém, é interessante notar que os pais participantes do estudo não somente procuravam garantir o bem-estar de suas companheiras, como também buscavam aproximar as mães dos bebês, quando necessário. Os pais estavam sensíveis às necessidades de seus filhos, entendendo o quão importante era para a mãe e para o desenvolvimento emocional primitivo do bebê manter uma relação próxima da dupla, tanto quanto possível.

Então, todos os pais participantes do estudo exerceram a paternidade como provedores de segurança e proteção às mães e, por conseqüência, à relação mãe-bebê. Além disso, procuraram substituir as companheiras em relação aos cuidados práticos e afetivos ao bebê, assumindo papéis muito próximos aos maternais. A maneira como eles se referiam aos bebês, o envolvimento, a preocupação com o bem-estar e proteção da criança denotava que os homens experienciam sentimentos tipicamente maternos, o que os aproxima da experiência da Constelação da Maternidade (Stern, 1997) vivenciada pelas mães, dado já constatado por Coutinho e 
Morsch (2006). Então, destaca-se que, no presente estudo, o envolvimento intenso dos pais em relação aos bebês, que surpreendeu pela afetividade, cuidado e amor, demonstrados por estes homens que estavam experimentando a paternidade pela primeira vez.

Para finalizar, cabe ressaltar que os pais e mães experienciaram a parentalidade de maneira bastante intensa, considerando as limitações impostas pela hospitalização. É possível perceber que os sentimentos, tarefas, preocupações e expectativas relativas à parentalidade ficaram exacerbadas e o empenho em manter vivo o bebê, atendendo às suas necessidades, fez com que estes pais e mães se dedicassem exclusivamente a essa experiência tão fundamental para a sobrevivência física e emocional do bebê.

\section{Referências}

Brazelton, T. B., \& Cramer, B.G. (1992). As primeiras relações. São Paulo: Martins Fontes.

Caron, N. A. (2000). O ambiente intra-uterino e a relação maternofetal. In N.A. Caron, (Ed.), A relação pais-bebê: da observação à clínica (pp. 119-134). São Paulo: Casa do Psicólogo.

Carey, L. K., Nicholson, B. C., \& Fox, R. A. (2002). Maternal factors related to parenting young children with congenital heart disease. Journal of pediatric nursing, 17(3), 174-183.

Cheuk, D. K. L., Wong, S. M. Y.,Choi, Y. P., Chau, Y. F., \& Cheung, Y. F. (2006). Parent's understanding of their child's congenital heart disease. Heart, 90, 435-439.

Coutinho, H. R. B., \& Morsch, D. S. (2006). A paternidade em cuidados intensivos neonatais. Revista da Sociedade Brasileira de Psicologia Hospitalar, 9(1), 55-69.

Freitas, W. de M. F., Coelho, E. de A. C., \& Silva, A. T. M. C. (2007). Sentir-se pai: a vivência masculina sob o olhar de gênero. Caderno de Saúde Pública, 23(1), 137-145.

Gardner, F.V., Freeman, N.H., Black, A.M.S., \& Angelini, G.D. (1996). Disturbed mother-infant interaction in association with congenital heart disease. Heart, 76, 56-59.

Gomes, A.G., \& Piccinini, C.A. (2005). A ultra-sonografia obstétrica e a relação materno-fetal em situações de normalidade e anormalidade fetal. Estudos de Psicologia, 22(4), 381-393.

Goldbeck, L., \& Melches, J. (2005). Quality of life in families of children with congenital heart disease. Quality of Life Research, 14, 1915-1924.

Goldbeck, L., \& Melches, J. (2006). The impact of the severity of disease and social disadvantage on quality of life in families with congenital cardiac disease. Cardiology Young, 16, 67-75.

Griffin, T. (2002). Supporting families of infants with congenital heart disease. Newborn and infant nursing Reviews, 2(2), 83-89.

Grupo de Interação Social, Desenvolvimento e Psicopatologia - GIDEP/ Núcleo de Infância e Família - NUDIF/UFRGS/ CNPq (1998a). Ficha de Contato Inicial. Instrumento não publicado. Instituto de Psicologia. Universidade Federal do Rio Grande do Sul.

Grupo de Interação Social, Desenvolvimento e Psicopatologia - GIDEP/ Núcleo de Infância e Família - NUDIF/UFRGS/ CNPq (1998b). Termo de Consentimento Livre e Esclarecido. Instrumento não publicado. Instituto de Psicologia. Universidade Federal do Rio Grande do Sul.
Grupo de Interação Social, Desenvolvimento e Psicopatologia - GIDEP/ Núcleo de Infância e Família - NUDIF/UFRGS/ CNPq (1998c). Ficha de Dados Demográficos. Instrumento não publicado. Instituto de Psicologia. Universidade Federal do Rio Grande do Sul.

Houzel, D. (2004). As implicações da parentalidade. In L. SolisPonton (Ed.), Ser pai, ser mãe, parentalidade: um desafio para o novo milênio (pp. 47-52). São Paulo: Casa do Psicólogo.

Jatene, M. B., Oliveira, P. M., \& Moysés, R. A. (2007). Cirurgia no primeiro ano de vida. Revista da Sociedade de Cardiologia do Estado de São Paulo, 17(2), 167-176.

Klaus, M., \& Kennell, J. (1992). Pais/bebê: a formação do apego. Porto Alegre: Artes Médicas.

Klaus, K,, Kennell, J. H., \& Klaus, P. (2000). Vinculo. Porto Alegre: Artmed.

Kovalchin, J. P., Silverman, N. H. (2004). The impact of fetal echocardiography. Pediatric Cardiology, 25, 299-306.

Kroeff, C. Q., Maia, C. R., \& Lima, C. P. (2000). O luto do filho malformado. Femina, 28(7), 395-396.

Lamb, M. E., Pleck, J. H., Charnov, E. L., \& Levine, J. A. (1985). Paternal behavior in humans. American Zoologist, 25(3), 883-894.

Laville, C., \& Dionne, J. (1999). A construção do saber: manual de metodologia da pesquisa em ciências humanas. Porto Alegre: Artes Médicas.

Lawoko, S., \& Soares, J. J. F. (2002). Distress and hopelessness among parents of children with congenital heart disease, parents of children with other diseases, and parents of healthy children. Journal of Psychosomatic Research, 52, 193-208.

Lebovici, S. (1992). Maternidade. In G. Costa (Ed.), Dinâmica das relações conjugais (pp. 41-61). Porto Alegre: Artes Médicas.

Lok, S. W., \& Menahem, S. (2004). Parental perception of small ventricular septal defects in childhood. Journal of Pediatric Child Health 40, 180-183.

Maldonado, M. T. P. (1997). Psicologia da gravidez. Petrópolis: Vozes.

Menahem, S., \& Grimwade, J. (2005). Pre-natal counseling-helping couples make decisions following the diagnosis of severe heart disease. Early Human Development, 81(7) Jul 2005, 601-607.

Oiberman, A. (1994). La relacion padre-bebe: una revision bibliográfica. Revista Hospital Materno Infantil Ramón Sarda, $\operatorname{XVIII}(2), 66-72$.

Pelchat, J., Ricard, N., Bouchard, J., Perreault, M., Saucier, J., Berthiaume, M., \& Bisson J. (1999). Adaptation of parents on relation to their 6-month-old infant's type of disability. Child: Care, Health and Development, 25(4), 377-397.

Quayle, J. Isfer, E., \& Zugaib, M. (1991). Considerações acerca das representações associadas ao diagnóstico pré-natal. Revista de Ginecologia e Obstetrícia, 2(1), 34-38.

Quayle, J., Neder, M., Mihaydaira, S., \& Zugaib, M. (1996). Repercussões na família do diagnóstico de malformações fetais: algumas reflexões. Revista de Ginecologia e Obstetrícia, 7(1), 33-39.

Quayle, J. (1997). Parentalidade e medicina fetal: repercussões emocionais. In. M. Zugaib, M. Brizot, V. Bunduki, \& D. Pedreira (Eds.), Medicina Fetal: Atheneu.

Racamier, P. C. (1961). La mère et l'enfant dans les psychoses du post-partum. L'evolutionary Psychiatry 26(4), 525-569. 
Ribeiro, C., \& Madeira, A. M. F. (2006). O significado de ser mãe de um filho portador de cardiopatia: um estudo fenomenológico. Revista da Escola de Enfermagem, 40(1), 42-49.

Rona, R. J., Smeeton, N. C., Beech, R., Barnett, A., \& Sharland, G. (1998). Anxiety and depression in mothers related to severe malformation of the heart of the child and foetus. Acta Paediatr, 87, 201-205.

Silva, M. R., \& Piccinini, C. A. (2007). Sentimentos sobre a paternidade e o envolvimento paterno: um estudo qualitativo. Estudos de Psicologia, 24(4), 561-573.

Stake, R. (1994). Case studies. In N. Denzin, \& Y. Lincoln (Eds.), Handbook of qualitative research (pp. 236-247). London: Sage.

Soifer, R. (1980). Psicologia da gravidez, parto e puerpério. Porto Alegre: Artes Médicas.

Soulé, M. (1987). O filho da cabeça, o filho imaginário. In T. Brazelton, B. Cramer, L. Kreisler, R. Schappi, \& M. Soulé (Eds.), A dinâmica do bebê (pp.132-170). Porto Alegre: Artes Médicas.

Stern, D. N. (1997). A constelação da maternidade: o panorama da psicoterápica pais-bebê. Porto Alegre: Artes Médicas.

Svavarsdottir, E. K., \& McCubbing, M. (1996). Parenthood transition for parents of an infant diagnosed with a congenital heart condition. Journal of Pediatric Nursing: nursing care of children \& families, 11(4), 207-216.
Szejer, M., \& Stewart, R. (1997). Nove meses na vida da mulher. São Paulo: Casa do Psicólogo.

Uzark, K., \& Jones, K. (2003). Parenting stress and children with heart disease. Journal of pediatric health care, 17, 163-168.

Winnicott, D. W. (1988). Preocupação materna primária. In D. W. Winnicott (Ed.), Textos selecionados: da pediatria à psicanálise (pp. 491-498). São Paulo: Imago. (Original published in 1956)

Wray, J., \& Maynard, L. (2004). Living with congenital or acquired cardiac disease in childhood: maternal perceptions of the impact on the child and family. Cardiology Young, 15, 133-140.

Recebido em 22.07.2009

Primeira decisão editorial em 30.09.2009

Versão final em 14.09.2011

Aceito em 14.09.2011

\section{Curso: Psicologia Hospitalar do Hospital das Clí́nicas da Faculdade de Medicina da USP}

São Paulo, SP, BR

5 de Março de 2012 a 5 de Abril de 2013 